\title{
Trends in mitral valve prolapse: a tertiary care center experience in Jeddah, Saudi Arabia
}

This article was published in the following Dove Medical Press journal: International Journal of General Medicine

\section{Ahmed Hussein Subki Mahmoud Ghaleb Bakhaidar Moaz Abdulrahman \\ Bakhaider \\ Ali Abdulrahman \\ Alkhowaiter \\ Rakan Salah Al-Harbi Mohammed Ali Almalki Khalid Abdullah Alzahrani Maged Mazen Fakeeh Siham Hussein Subki Wesam Awad Alhejily}

Department of Internal Medicine, College of Medicine, King Abdulaziz University, Jeddah, Saudi Arabia
Correspondence: Wesam Awad Alhejily Department of Internal Medicine, College of Medicine, King Abdulaziz University, PO Box 43129, Jeddah 21561, Saudi Arabia

Tel +966546033322

Email walhejily@kau.edu.sa
Background: Mitral valve prolapse (MVP) is the most common cardiac valvular abnormality in developed countries and it is associated with considerable morbidity and mortality.

Aim of work: To study the clinical presentations, risk factors, and echocardiographic features of patients with MVP in Jeddah, Saudi Arabia.

Materials and methods: A retrospective chart review study was conducted in King Abdulaziz teaching hospital in Jeddah, Saudi Arabia, from 2007 to 2017. All patients with MVP who were admitted at the hospital during this time period were recruited to this study, and demographic, clinical, and echocardiographic variables were analyzed using IBM SPSS.

Results: Ninety-seven patients were recruited to this study, with a mean age of $43.82 \pm 16.16$ years. Females constituted $67 \%$. The body mass index (BMI) was $24.9 \pm 6.3 \mathrm{~kg} / \mathrm{m}^{2}$. Hypertension, diabetes, and dyslipidemia occurred in $19.6 \%, 5.2 \%$, and $5.2 \%$ of patients, respectively. A single patient had Marfan syndrome. Chest pain, palpitations, and dyspnea were the presenting symptoms in $23.7 \%, 11.3 \%$, and $9.3 \%$ of patients, respectively, with elderly individuals presenting disproportionally $(93.3 \%)$ with palpitations. Fifty-five percent of patients had an anterior leaflet prolapse. The presence of posterior leaflet prolapse and severe mitral regurgitation (MR) was significantly associated with left atrial and left ventricular dilatation $(P<0.05$ and $P<0.001$, respectively).

Conclusion: MVP is more prevalent in women and middle-aged individuals with normal BMIs in this population. The most common clinical presentations were chest pain, palpitations, and dyspnea, which did not differ significantly with age or gender. The anterior leaflet was the most commonly prolapsed in the studied patients and presented with mild MR. Posterior leaflet MVP, while of low prevalence, was associated with severe MR and poor left ventricular function.

Keywords: clinical presentation, echocardiography, mitral valve prolapse, prevalence, risk factors

\section{Introduction}

Mitral valve prolapse (MVP), a clinical entity that has been described in the medical literature for over a century, has undergone significant changes in its name, diagnostic criteria, and management approach. ${ }^{1,2}$ MVP impacts $\sim 7.8$ million individuals in the USA and over 176 million people worldwide. ${ }^{2}$ Echocardiography is established as the gold standard for diagnosing MVP and evaluating its hemodynamic sequel. ${ }^{3}$ The diagnostic criteria consist of billowing of one or both mitral leaflets at least $2 \mathrm{~mm}$ beyond the echocardiographic parasternal long-axis annular plane. ${ }^{4}$ Mitral leaflets can 
further be categorized as myxomatous or redundant if the thickness is $5 \mathrm{~mm}$ or more. ${ }^{5}$ These valvular abnormalities are associated with significant clinical complications such as congestive heart failure, bacterial endocarditis, cerebral emboli, arrhythmias, and sudden death, ${ }^{6-10}$ which significantly alters prognosis. MVP is the most common cardiac valvular abnormality in industrialized countries and the leading cause for nonischemic and isolated mitral regurgitation (MR) requiring surgical intervention. ${ }^{11-13}$ In addition, diagnosis of MVP may cause untold societal burden due to associated anxiety, which may impact individuals' personal and professional life. ${ }^{11}$

In early research on MVP, the prevalence in the general population varied between $5 \%$ and $15 \%$, reaching up to $35 \%$ in some studies. ${ }^{14}$ This variation was likely due to technological limitations and poorly defined criteria used for diagnosis. ${ }^{15}$ With the implementation of the currently modified criteria of MVP and an improved understanding of mitral valve anatomy, the published prevalence of MVP has significantly decreased. ${ }^{14,15}$ In accordance, the Framingham Heart Study reported an overall prevalence of $2 \%-3 \% .{ }^{15}$ However, there is still a variation in MVP prevalence across studies, which may be due to methodical differences in study design or population differences secondary to the variation in genetic and environmental predispositions. ${ }^{11,16}$ Studies by Flack et al and Hepner et al estimated MVP prevalence of $<1 \%$, which is significantly lower than the prevalence reported in the Framingham Heart Study. ${ }^{16,17}$ The MELEN study concluded the prevalence to be only $0.36 \%$ in their population. ${ }^{18}$ In Saudi Arabia, a study conducted at King Abdulaziz Medical City revealed a prevalence of $0.33 \%$, which is less than previously published results from studies conducted in Saudi Arabia. ${ }^{19-22}$

To the best of our knowledge, the prevalence and characteristics of MVP have not been studied at King Abdulaziz University Hospital since $1992 .{ }^{23}$ Therefore, in light of the scarcity of current research regarding this topic in the Saudi population, and specifically in this hospital, we aimed to determine the prevalence and characteristics of MVP in a tertiary care center experience here at King Abdulaziz University Hospital in Jeddah.

\section{Materials and methods}

A retrospective chart review was conducted at King Abdulaziz teaching hospital in Jeddah, Saudi Arabia. All medical records of patients with cardiac diseases who were admitted to the hospital during the 11-year period from 2007 to 2017 were reviewed, and all patients with an echocardiographyconfirmed diagnosis of MVP were recruited to the study. The echocardiographic diagnostic criteria for MVP considered for recruitment of patients for this study were superior displacement of mitral valve leaflets $2 \mathrm{~mm}$ or more toward the left atrial (LA) cavity during systole and a valve leaflet thickness of at least $5 \mathrm{~mm} .{ }^{24}$ There were no exclusion criteria for recruitment, and all ages were eligible. The data sheet used to collect information from the medical record included demographic data (such as age, sex, body mass index [BMI], and nationality), clinical presentations (including chest pain, palpitation, dyspnea, syncope, or asymptomatic presentation), risk factors and associated comorbidities (such as skeletal deformities, connective tissue diseases, diabetes mellitus, hypertension, and dyslipidemia), and echocardiographic findings (including left ventricular end-diastolic dimension [LVd], left ventricular end-systolic dimension [LVESD], left ventricular [LV] dimension fraction shortening [FS], LA size, and ejection fraction [EF]).

All demographic, clinical, and echocardiographic data were analyzed using IBM SPSS software version 20.0 (IBM Corporation, Armonk, NY, USA). Categorical variables were described using frequencies and percentages, and quantitative variables were presented using mean, range, and SD. Correlations between various demographic, clinical, and echocardiographic variables were carried out using the Spearman rank correlation test. Comparison between cardiac symptoms and gender was done by the chi-squared test. Comparison between cardiac symptoms and age groups was done by one-way ANOVA. Again, the one-way ANOVA tests were used to compare valve leaflet types and MR degree to echocardiogram parameters. Significance of the analyzed data was set at 95\% CI and 5\% probability value level.

This study was approved by the Unit of Biomedical Ethics Research Committee at King Abdulaziz University, and it was conducted in accordance with the Declaration of Helsinki. Patient consent to review their medical records was not required by the ethics committee. This waiver was due to the retrospective chart review nature of our study. No personal data that could reveal a patient entity were used. Patient data were strictly protected for confidentiality when conducting this study.

\section{Results}

A total of 97 patients with echocardiography-confirmed MVP were included in the retrospective chart review. The mean age of the patients included in this study was $43.82 \pm 16.16$ years with a range of 17 and 94 years. Two-thirds of the patients $(67.0 \%)$ were females and a majority $(55.7 \%)$ were citizens of Saudi Arabia. The mean BMI of the studied patients was 
$24.97 \pm 6.27 \mathrm{~kg} / \mathrm{m}^{2}$ with a range of 14.21 and $56.14 \mathrm{~kg} / \mathrm{m}^{2}$ (Table 1).

The main cardiac risk factors in the studied population were hypertension, diabetes mellitus, and dyslipidemia found in $19.6 \%, 5.2 \%$, and $5.2 \%$ of the patients, respectively. None of the patients had scoliosis, other skeletal disorders, thyroid disorder, or a history of rheumatic fever. One patient each had a medical history significant for Marfan syndrome, Down's syndrome, and congenital heart disease. HIV+ status and hypereosinophilic syndrome were each noted in a single patient.

The clinical presentations of MVP were chest pain, palpitations, dyspnea, and syncope found in $23.7 \%, 11.3 \%, 9.3 \%$ and $5.2 \%$ cases, respectively. Among the 32 male patients in this study, 8 (25.0\%) had chest pain, 3 (9.4\%) had palpitations, 4 (12.5\%) had dyspnea, and 1 (3.1\%) had syncope. Among the 65 female patients in this study, 15 (23.1\%) had chest pain, $8(12.3 \%)$ had palpitations, $5(7.7 \%)$ had dyspnea, and 4 (6.2\%) had syncope. None of the recruited

Table I Demographic characteristics of all patients $(n=97)$

\begin{tabular}{|l|l|}
\hline Characteristics & N (\%) \\
\hline Age in years (mean \pm SD) & $43.82 \pm 16.16$ \\
Gender & \\
Male & $32(33.0)$ \\
Female & $65(67.0)$ \\
Nationality & \\
Saudi & $54(55.7)$ \\
Non-Saudi & $43(44.3)$ \\
BMI in kg/m $/ \mathrm{m}^{2}$ mean \pm SD) & $24.97 \pm 6.27$ \\
\hline
\end{tabular}

Abbreviation: BMI, body mass index. patients had an asymptomatic presentation of MVP. The chisquared test revealed no statistically significant difference between males and females in terms of clinical presentation (Table 2). A total of 22 patients were diagnosed at age 30 years or younger. Among this group, five $(22.7 \%)$ had chest pain, three (13.6\%) had palpitations, three (13.6\%) had dyspnea, and one (4.5\%) had syncope. Sixty patients were diagnosed between ages 31 and 60 years. Fifteen $(25.0 \%)$ had chest pain, eight (13.3\%) had palpitations, five (8.3\%) had dyspnea, and two (3.3\%) had syncope. The number of patents aged 61 years and older ( maximum age $=94$ years) was 15 . Only 3 of them (20.0\%) had chest pain, 14 (93.3\%) had palpitations, 1 (6.7\%) had dyspnea, and 2 (13.3\%) had syncope. There was no statistically significant difference between the age groups in terms of chest pain, palpitations, dyspnea, or syncope (Table 3).

In almost half of the patients' files (47.4\%), there was no clear indication for requesting an echocardiography beyond the health care provider's documented request. Among the remaining half, echocardiography was indicated for clinical suspicion of MVP in 17 (17.5\%) cases and for chest pain in $9(9.3 \%)$ cases. With regard to the echocardiographic parameters, the mean LVd for all patients was $4.93 \pm 0.68$ $\mathrm{cm}$, the mean LVESD was $3.20 \pm 0.55 \mathrm{~cm}$, the mean EF was $63.43 \% \pm 7.88 \%$, the mean FS was $34.84 \pm 5.91 \mathrm{~cm}$, and the mean LA size was $3.60 \pm 0.79 \mathrm{~cm}$ (Table 4). Only one patient had mitral stenosis. There was a variety of prolapse types: $54.6 \%$ had anterior mitral leaflet prolapse, $27.8 \%$ had posterior leaflet prolapse, and $17.5 \%$ had both leaflets prolapsed. Flail leaflet was noticed in $5.2 \%$ of the cases, but none of the patients had ruptured chordae. The degree of the MR

Table 2 Frequencies and percentages of chest pain, palpitation, dyspnea, and syncope in all patients $(n=97)$, males ( $n=32)$, and females $(n=65)$ and comparison between both gender by chi-squared test

\begin{tabular}{|l|l|l|l|l|l|}
\hline Symptoms & All patients (n=97), N (\%) & Male (n=32), N (\%) & Female (n=65), N (\%) & OR & P-value \\
\hline Chest pain & $23(23.7)$ & $2(25.0)$ & $15(23.1)$ & 1.111 & 0.834 \\
Palpitation & II (II.3) & $3(9.4)$ & $8(12.3)$ & 0.763 & 0.705 \\
Dyspnea & $9(9.3)$ & $4(12.5)$ & $5(7.7)$ & 1.778 & 0.413 \\
Syncope & $5(5.2)$ & I (3.1) & $4(6.2)$ & 0.508 & 0.546 \\
\hline
\end{tabular}

Table 3 Distribution of chest pain, palpitation, dyspnea, and syncope in all patients and age categories and comparison of age categories by one-way ANOVA

\begin{tabular}{|c|c|c|c|c|c|}
\hline Symptoms & $\begin{array}{l}\text { All patients } \\
(n=97), N(\%)\end{array}$ & $\begin{array}{l}\text { Age } 0-30 \text { years } \\
(n=22), N(\%)\end{array}$ & $\begin{array}{l}\text { Age } 3 \mathrm{I}-60 \text { years } \\
(n=60), N(\%)\end{array}$ & $\begin{array}{l}\text { Age } \geq 6 \mid \text { years }(n=15), \\
N(\%)\end{array}$ & $P$-value \\
\hline Chest pain & $23(23.7)$ & $5(22.7)$ & $15(25.0)$ & $3(20.0)$ & 0.916 \\
\hline Palpitation & II (II.3) & $3(13.6)$ & $8(13.3)$ & $14(93.3)$ & 0.354 \\
\hline Dyspnea & $9(9.3)$ & $3(13.6)$ & $5(8.3)$ & I (6.7) & 0.737 \\
\hline Syncope & $5(5.2)$ & I (4.5) & $2(3.3)$ & $2(13.3)$ & 0.255 \\
\hline
\end{tabular}


Table 4 Distribution of patients according to their echocardiographic parameters $(n=97)$

\begin{tabular}{|l|l|l|l|l|}
\hline Parameter & Mean & SD & Min & Max \\
\hline LVd & 4.93 & \pm 0.68 & 3.62 & 7.44 \\
LVESD & 3.20 & \pm 0.55 & 2.08 & 5.48 \\
EF & 63.43 & \pm 7.88 & 42.00 & 80.00 \\
FS & 34.84 & \pm 5.91 & 21.00 & 48.00 \\
LA size & 3.60 & \pm 0.79 & 2.04 & 5.80 \\
\hline
\end{tabular}

Abbreviations: $E F$, ejection fraction; $F S$, fraction shortening; LA, left atrial; LVd, left ventricular end-diastolic dimension; LVESD, left ventricular end-systolic dimension.

was trivial in $13.4 \%$, mild in $45.4 \%$, moderate in $32.0 \%$, and severe in $7.2 \%$ of the recruited patients. Almost one-third of the patient (32.0\%) had a thickened mitral valve leaflet. One patient had LV hypertrophy, whereas none had decreased LV systolic function. Mild increase in LV internal cavity was reported in $5.2 \%$ cases, while a severe increase was reported in $4.1 \%$ cases (Table 5 ). The correlations between different demographic, clinical, and echocardiographic variables are detailed in Table 6 .

When echocardiographic parameters were compared across the leaflet types, we observed a statistically significant difference in LVd $(P<0.001)$, LVESD $(P=0.008)$, and LA size $(P<0.001)$. Of note, the posterior leaflet type was associated with the highest values of LVd, LVESD, and LA size. EF and FS were statistically similar across different leaflet types (Table 7). In contrast, LVd $(P<0.001)$, LVESD $(P<0.001)$, and LA size $(P<0.001)$ were significantly different across different degrees of MR. Moderate and severe degrees of MR were associated with higher LVd, LVESD, and larger LA size, whereas there was no statistically significant difference in EF and FS across degrees of MR (Table 8).

\section{Discussion}

In this retrospective review, 97 patients were identified with MVP, with a mean age of $43.82 \pm 16.16$ years. MVP often occurs in adulthood and increases with age. Aging is associated with degenerative changes in the valvular leaflets and therefore, higher rates of valve prolapse. In this study, the mean age of diagnosis is higher than what is reported among various literature. ${ }^{13,14}$ This may be due to different sample characteristics, and it may also reflect a selection bias as it will be noted at the end of discussion. In this study, we identified age as a significant correlate of worse echocardiographic parameters, namely LVd and LA size $(P<0.05)$. Females constituted the vast majority of the patients, which is in agreement with the medical literature that reports a higher prevalence in women. ${ }^{25,26}$ Although females have
Table 5 Distribution of patients according to the mitral valverelated variables $(n=97)$

\begin{tabular}{|l|l|l|}
\hline Variables & Frequency & Percentage \\
\hline Mitral stenosis & $\mathrm{I}$ & 1.0 \\
\hline Prolapsed leaflet & & \\
$\quad$ Anterior & 53 & 54.6 \\
Posterior & 27 & 27.8 \\
Both & 17 & 17.5 \\
\hline Flail leaflet & 5 & 5.2 \\
\hline Ruptured chordae & 0 & 0.0 \\
\hline Degree of MR & & \\
Trivial & 13 & 13.4 \\
$\quad$ Mild & 44 & 45.4 \\
$\quad$ Moderate & 31 & 32.0 \\
Severe & 7 & 7.2 \\
\hline Thickness of mitral valve leaflet & $3 \mathrm{I}$ & 32.0 \\
\hline Decreased LVSF & 0 & 0.0 \\
\hline LV hypertrophy & $\mathrm{I}$ & 1.0 \\
\hline Increased LV internal cavity & & \\
$\quad$ Mild & 5 & 5.2 \\
Severe & 4 & 4.1 \\
\hline
\end{tabular}

Abbreviations: $L V$, left ventricle; LVSF, left ventricular systolic function; MR, mitral regurgitation.

Table 6 Correlations between different demographic, clinical, and echocardiographic variables using Pearson's coefficient (at $95 \% \mathrm{Cl})(\mathrm{n}=97)$

\begin{tabular}{|l|l|l|}
\hline Variable & Correlation with & $\boldsymbol{P}$-value \\
\hline Age & BMI & 0.027 \\
& LVd & 0.027 \\
& LA size & $<0.00$ I \\
\hline Gender & LVd & $<0.00$ I \\
& LVESD & $<0.00$ I \\
& LA size & $<0.00$ I \\
\hline BMI & LVd & 0.001 \\
& LVESD & 0.026 \\
& LA size & 0.001 \\
\hline DM & Chest pain & 0.002 \\
\hline Dyspnea & Chest pain & 0.014 \\
& Palpitation & $<0.001$ \\
& LVESD & 0.025 \\
& Flail leaflet & 0.016 \\
\hline LVd & LVESD & $<0.001$ \\
& LA size & $<0.00$ I \\
& Flail leaflet & $<0.00$ I \\
\hline LVESD & LA size & $<0.001$ \\
& Flail leaflet & $<0.001$ \\
\hline LA size & Flail leaflet & 0.004 \\
\hline
\end{tabular}

Abbreviations: BMI, body mass index; DM, diabetes mellitus; LA, left atrial; LVd, left ventricular end-diastolic dimension; LVESD, left ventricular end-systolic dimension.

milder grades of mitral prolapse and lower rates of surgical interventions, they suffer from higher mortality rates. ${ }^{25} \mathrm{We}$ noted similar results in this study as gender was significantly correlated with the echocardiographic measures, specifically 
Table 7 Comparison between echocardiographic parameters and prolapsed leaflet type $(n=97)$

\begin{tabular}{|c|c|c|c|c|c|}
\hline Echo parameters & Leaflet type & Mean \pm SD & $95 \% \mathrm{Cl}$ & $\boldsymbol{F}$ & $P$-value \\
\hline LVd & $\begin{array}{l}\text { Anterior } \\
\text { Posterior } \\
\text { Both }\end{array}$ & $\begin{array}{l}4.64 \pm 0.55 \\
5.32 \pm 0.82 \\
5.22 \pm 0.35\end{array}$ & $\begin{array}{l}4.79-4.49 \\
5.64-5.00 \\
5.40-5.04\end{array}$ & 13.140 & $<0.001$ \\
\hline LVESD & $\begin{array}{l}\text { Anterior } \\
\text { Posterior } \\
\text { Both }\end{array}$ & $\begin{array}{l}3.05 \pm 0.44 \\
3.42 \pm 0.68 \\
3.31 \pm 0.55\end{array}$ & $\begin{array}{l}3.17-2.92 \\
3.69-3.15 \\
3.55-3.07\end{array}$ & 5.135 & 0.008 \\
\hline $\mathrm{EF}$ & $\begin{array}{l}\text { Anterior } \\
\text { Posterior } \\
\text { Both }\end{array}$ & $\begin{array}{l}62.61 \pm 6.86 \\
64.13 \pm 8.45 \\
64.91 \pm 9.95\end{array}$ & $\begin{array}{l}64.50-60.72 \\
67.54-60.71 \\
70.02-59.79\end{array}$ & 0.680 & 0.509 \\
\hline FS & $\begin{array}{l}\text { Anterior } \\
\text { Posterior } \\
\text { Both }\end{array}$ & $\begin{array}{l}33.95 \pm 5.00 \\
35.74 \pm 6.35 \\
36.18 \pm 7.55\end{array}$ & $\begin{array}{l}35.33-32.57 \\
38.25-33.23 \\
40.06-32.30\end{array}$ & 1.356 & 0.263 \\
\hline LA & $\begin{array}{l}\text { Anterior } \\
\text { Posterior } \\
\text { Both }\end{array}$ & $\begin{array}{l}3.19 \pm 0.62 \\
4.16 \pm 0.70 \\
3.98 \pm 0.67\end{array}$ & $\begin{array}{l}3.36-3.02 \\
4.44-3.88 \\
4.33-3.62\end{array}$ & 22.870 & $<0.001$ \\
\hline
\end{tabular}

Abbreviations: EF, ejection fraction; FS, fraction shortening; LA, left atrial; LVd, left ventricular end-diastolic dimension; LVESD, left ventricular end-systolic dimension.

Table 8 Comparison between echocardiographic parameters and MR degree $(n=97)$

\begin{tabular}{|c|c|c|c|c|c|}
\hline Echo parameters & MR degree & Mean \pm SD & $95 \% \mathrm{Cl}$ & $F$ & $P$-value \\
\hline LVd & $\begin{array}{l}\text { Trivial } \\
\text { Mild } \\
\text { Moderate } \\
\text { Severe }\end{array}$ & $\begin{array}{l}4.68 \pm 0.53 \\
4.69 \pm 0.58 \\
5.09 \pm 0.44 \\
6.19 \pm 0.98\end{array}$ & $\begin{array}{l}5.00-4.36 \\
4.87-4.51 \\
5.25-4.93 \\
7.10-5.28\end{array}$ & 15.748 & $<0.001$ \\
\hline LVESD & $\begin{array}{l}\text { Trivial } \\
\text { Mild } \\
\text { Moderate } \\
\text { Severe }\end{array}$ & $\begin{array}{l}3.18 \pm 0.36 \\
3.03 \pm 0.50 \\
3.23 \pm 0.39 \\
4.09 \pm 0.90\end{array}$ & $\begin{array}{l}3.39-2.96 \\
3.18-2.88 \\
3.38-3.09 \\
4.93-3.26\end{array}$ & 9.651 & $<0.001$ \\
\hline EF & $\begin{array}{l}\text { Trivial } \\
\text { Mild } \\
\text { Moderate } \\
\text { Severe }\end{array}$ & $\begin{array}{l}60.55 \pm 4.73 \\
63.68 \pm 7.84 \\
64.97 \pm 8.50 \\
59.85 \pm 10.40\end{array}$ & $\begin{array}{l}63.41-57.69 \\
66.07-61.30 \\
68.09-61.85 \\
70.76-48.94\end{array}$ & 1.395 & 0.250 \\
\hline FS & $\begin{array}{l}\text { Trivial } \\
\text { Mild } \\
\text { Moderate } \\
\text { Severe }\end{array}$ & $\begin{array}{l}32.26 \pm 3.48 \\
34.98 \pm 5.66 \\
36.09 \pm 6.56 \\
33.27 \pm 7.97\end{array}$ & $\begin{array}{l}34.36-30.16 \\
36.70-33.26 \\
38.50-33.69 \\
40.65-25.90\end{array}$ & 1.455 & 0.232 \\
\hline LA & $\begin{array}{l}\text { Trivial } \\
\text { Mild } \\
\text { Moderate } \\
\text { Severe }\end{array}$ & $\begin{array}{l}3.20 \pm 0.55 \\
3.28 \pm 0.62 \\
3.98 \pm 0.66 \\
4.87 \pm 0.67\end{array}$ & $\begin{array}{l}3.53-2.87 \\
3.47-3.09 \\
4.23-3.74 \\
5.49-4.26\end{array}$ & 18.779 & $<0.001$ \\
\hline
\end{tabular}

Abbreviations: EF, ejection fraction; FS, fraction shortening; LA, left atrial; LVd, left ventricular end-diastolic dimension; LVESD, left ventricular end-systolic dimension; MR, mitral regurgitation.

LVd, LVESD, and LA size. The mechanisms behind this gender differences in MVP remain elusive.

Acquired MVP can present secondary to various etiologies. The most common is myxomatous degeneration, due to deposition of proteoglycans in the mitral valve leaflets. This primarily affects patients with connective tissue diseases or advanced age. The next most common are inflammatory etiologies, with rheumatoid heart disease serving as the prototype disease leading to MVP. In this study, the majority of the recruited patients had a BMI within normal range, with a mean of $24.9 \pm 6.27 \mathrm{~kg} / \mathrm{m}^{2}$. This is similar to reports in the medical literature. ${ }^{14,19,25}$ Patients with MVP are characteristically tall and lean, which is attributed to the specific structure of connective tissue in these patients. ${ }^{3,16}$ Marfan syndrome is one of the common connective tissue diseases associated with MVP and was found in one of the studied 
patients. ${ }^{27}$ However, other connective tissue diseases such as Ehlers-Danlos syndrome, myxomatous disorders, Grave's disease, skeletal deformities such as scoliosis, and history of rheumatic fever were not found in our recruited subjects.

While hypertension, diabetes, and dyslipidemia were found to be commonly associated comorbidities in our study, even though they are not related to the etiology of mitral valve relapse, they may worsen the prognosis of the disease. ${ }^{28}$ Rossi et al, in their retrospective study of 814 patients with mitral valve disease, reported that these three factors were significantly associated with poor outcome and higher mortality rate..$^{29}$ In the study, hypertension had a HR for mortality of $1.48(P=0.01)$. Diabetes and hyperlipidemia were associated with HR for mortality of $1.04(P<0.001)$ and $1.68(P=0.005)$, respectively. Similarly, Ernande et al reported a significant negative effect of diabetes mellitus on LV function and remodeling in patients with MVP. ${ }^{30}$ In this research, both diabetes and dyslipidemia were significantly associated with the clinical presentation of chest pain, and dyslipidemia was also associated with increased rates of palpitation and worse LV dimensions. This literature supports the poor outcome we noted in our subjects with these comorbidities.

The most common clinical presentations in our subjects were chest pain (23.7\%), palpitations (11.3\%), and dyspnea $(9.3 \%)$, with syncope occurring in only $5.2 \%$. Importantly, while clinical presentation varied across gender, this was not statistically significant $(P>0.05)$. Chest pain was the most common presentation in both genders, but males experienced more dyspnea and females experienced more palpitations. The difference in clinical presentation between genders is likely attributed to the anatomical differences in mitral valve leaflet position and cardiac myometrial structure. ${ }^{31}$ Age also seems to affect clinical presentation. Elderly individuals were prone to more palpitations and syncope compared with younger patients. Although similar findings are not clearly reproduced in the MVP literature, many researchers noted pathophysiologic changes that occur in mitral valve leaflets with age. The higher prevalence of syncope and palpitation in the elderly may be attributed to the scarring and tethering of the valvular leaflets and chordae and the associated alteration in valvular and ventricular geometry and function that occurs over time. ${ }^{31,32}$

The most commonly affected leaflet in our sample was the anterior leaflet (54.6\%). The posterior leaflet was affected in $27.8 \%$ and both leaflets in $17.5 \%$ of recruited patients. While involvement of the posterior leaflet was less common, it was significantly associated with increased LVESD $(P<0.001)$ and $\operatorname{LVd}(P=0.008)$ and larger LA sizes $(P<0.001)$. In reviewing the literature, anterior leaflet prolapse is more prevalent among females and is associated with mild grades of $\mathrm{MR}^{2}$ but confers a higher risk of residual MR after surgical valve repair. ${ }^{33}$ Concomitant MR is most predictive of poor outcome in patients with MVP. ${ }^{34}$ The majority of the recruited patients had trivial (13.4\%) or mild (45.4\%) MR, while moderate and severe MR was found in $32 \%$ and $7.2 \%$, respectively. Only $1 \%$ of patients had mitral stenosis. To assess the impact of MR degree on outcomes, a comparison was made between the four grades to determine the influence on ventricular and atrial dimensions. Patients with moderate and severe MR had worse ventricular function and subsequently higher LVd, LVESD, and LA sizes $(P<0.001)$. Among the studied sample, patients with posterior leaflet MVP and severe MR had poor LV function, likely due to the higher residual LV volume and MR during systole.

The main limitation of our study is the presence of unintended selection bias. We recruited all patients who were electronically registered after admission during the period between 2007 and 2017. However, not all admitted patients were fully registered and, therefore, the sample characteristics may not be suitable for generalization. Further multicentric cross-sectional studies are recommended to identify the clinical and echocardiographic characteristics of the Saudi population.

\section{Conclusion}

MVP is more prevalent among females in this Saudi population and occurs in middle-aged individuals with normal BMIs. The most common clinical presentation is chest pain, followed by palpitations and dyspnea. Males experienced more palpitation and less dyspnea than females, while the elderly presented more frequently with syncope and palpitations. However, these gender- and age-related differences were not statistically significant. The anterior leaflet was the most common leaflet prolapsed, and concomitant MR was mostly of a trivial or mild degree. Posterior leaflet mitral prolapse, while less prevalent, was significantly associated with worse LV function. Severe degrees of MR had a negative impact on LV and LA dimensions. Age, female gender, diabetes mellitus, and dyslipidemia were significantly correlated with LV and LA dimensions.

\section{Author contributions}

Authorship was decided by the supervising author based on merit. The supervising author and all other coauthors agree as to the order of authorship. All authors contributed toward data analysis, drafting and revising the paper, gave final approval of the version to be published and agree to be accountable for all aspects of the work. 


\section{Disclosure}

The authors report no conflicts of interest in this work.

\section{References}

1. Shah PM. Current concepts in mitral valve prolapse - diagnosis and management. J Cardiol. 2010;56(2):125-133.

2. Delling FN, Vasan RS. Epidemiology and pathophysiology of mitral valve prolapse: new insights into disease progression, genetics, and molecular basis. Circulation. 2014;129(21):2158-2170.

3. Guy TS, Hill AC. Mitral valve prolapse. Annu Rev Med. 2012;63(1): 277-292.

4. Katan O, Michelena HI, Avierinos JF, et al. Incidence and predictors of infective endocarditis in mitral valve prolapse: a population-based study. Mayo Clin Proc. 2016;91(3):336-342.

5. Marks AR, Choong CY, Sanfilippo AJ, Ferré M, Weyman AE. Identification of high-risk and low-risk subgroups of patients with mitral-valve prolapse. N Engl J Med. 1989;320(16):1031-1036.

6. Mills P, Rose J, Hollingsworth J, Amara I, Craige E. Long-term prognosis of mitral-valve prolapse. N Engl J Med. 1977;297(1):13-18.

7. Avierinos JF, Detaint D, Messika-Zeitoun D, Mohty D, Enriquez-Sarano M. Risk, determinants, and outcome implications of progression of mitral regurgitation after diagnosis of mitral valve prolapse in a single community. Am J Cardiol. 2008;101(5):662-667.

8. Avierinos J-F, Brown RD, Foley DA, et al. Cerebral ischemic events after diagnosis of mitral valve prolapse. Stroke. 2003;34(6): 1339-1344.

9. Basso C, Perazzolo Marra M, Rizzo S, et al. Arrhythmic mitral valve prolapse and sudden cardiac death. Circulation. 2015;132(7):556-566.

10. Zuppiroli A, Rinaldi M, Kramer-Fox R, Favilli S, Roman MJ, Devereux RB. Natural history of mitral valve prolapse. Am J Cardiol. 1995;75(15):1028-1032.

11. Freed LA, Benjamin EJ, Levy D, et al. Mitral valve prolapse in the general population. J Am Coll Cardiol. 2002;40(7):1298-1304.

12. Devereux RB, Kramer-Fox R, Kligfield P. Mitral valve prolapse: causes, clinical manifestations, and management. Ann Intern Med. 1989;111(4):305-317.

13. Hayek E, Gring C, Griffin B. Mitral valve prolapse. Lancet. 2005;365(9458): 507-518.

14. Freed LA, Levy D, Levine RA, et al. Prevalence and clinical outcome of mitral-valve prolapse. N Engl J Med. 1999;341(1):1-7.

15. Buffon A, Biasucci LM, Liuzzo G, D’Onofrio G, Crea F, Maseri A. Widespread coronary inflammation in unstable angina. $N$ Engl J Med. 2002;347(1):5-12.

16. Hepner AD, Ahmadi-Kashani M, Movahed MR. The prevalence of mitral valve prolapse in patients undergoing echocardiography for clinical reason. Int J Cardiol. 2007;123(1):55-7

17. Flack JM, Kvasnicka JH, Gardin JM, Gidding SS, Manolio TA, Jacobs DR. Anthropometric and physiologic correlates of mitral valve prolapse in a biethnic cohort of young adults: the CARDIA study. Am Heart J. 1999;138(3 Pt 1):486-492.

18. Tagarakis GI, Karantzis I, Tsolaki F, Stylianakis GE, Daskalopoulos ME, Tsilimingas NB. Classic and non-classic forms of mitral valve prolapse. Anadolu Kardiyol Derg. 2012;12(1):2-4.
19. Nouh MS, Al-Nozha MM, Arafa MR, Alsubahi SA, Allam AK, Yamani HA. Clinical spectrum of skeletal abnormalities and mitral valve prolapse and their clinical implications. Ann Saudi Med. 1996;16(3): 266-268.

20. Turker Y, TurkerY, Baltaci D, et al; Melen Investigators. The prevalence and clinical characteristics of mitral valve prolapse in a large populationbased epidemiologic study: the MELEN study. Eur Rev Med Pharmacol Sci. 2015;19(12):2208-2212.

21. Al Ghamdi MG, Al Khodair YO, Al KAK. Prevalence and characteristics of mitral valve prolapse in adult echocardiography population in King Abdulaziz medical city over a 10 year period. Int J Acad Sci Res. 2018;4(4):2272-6446.

22. Nouh MS, Al-Nozha MM, Taha A, et al. Prevalence of bicuspid aortic valve and mitral valve prolapse in a healthy Saudi population and the clinical implications of their association. Ann Saudi Med. 1996;16(4):417-419.

23. Marzouki KMH, Zawawi TH, Khan AS. Mitral valve prolapse--experience at King Abdulaziz University Hospital. Available from: https:// authman.kau.edu.sa/Files/140/Researches/61774_32739.pdf. Accessed June 13, 2018

24. Perloff JK, Child JS, Edwards JE. New guidelines for the clinical diagnosis of mitral valve prolapse. Am J Cardiol. 1986;57(13):1124-1129.

25. Avierinos JF, Inamo J, Grigioni F, Gersh B, Shub C, Enriquez-Sarano M. Sex differences in morphology and outcomes of mitral valve prolapse. Ann Intern Med. 2008;149(11):787-794.

26. Enriquez-Sarano M, Akins CW, Vahanian A. Mitral regurgitation. Lancet. 2009;373(9672):1382-1394.

27. Bhudia SK, Troughton R, Lam BK, et al. Mitral valve surgery in the adult Marfan syndrome patient. Ann Thorac Surg. 2006;81(3) 843-848.

28. Jouan J, Tapia M, C Cook R, Lansac E, Acar C. Ischemic mitral valve prolapse: mechanisms and implications for valve repair. Eur J Cardiothorac Surg. 2004;26(6):1112-1117.

29. Rossi A, Zoppini G, Benfari G, et al. Mitral regurgitation and increased risk of all-cause and cardiovascular mortality in patients with type 2 diabetes. Am J Med. 2017;130(1):70-76.e1.

30. Ernande L, Beaudoin J, Piro V, Meziani S, Scherrer-Crosbie M. Adverse impact of diabetes mellitus on left ventricular remodelling in patients with chronic primary mitral regurgitation. Arch Cardiovasc Dis. 2018;111(8-9):487-496.

31. Levy D, Savage D. Prevalence and clinical features of mitral valve prolapse. Am Heart J. 1987;113(5):1281-1290.

32. Devereux RB, Kramer-Fox R, Brown WT, et al. Relation between clinical features of the mitral prolapse syndrome and echocardiographically documented mitral valve prolapse. J Am Coll Cardiol. 1986;8(4):| 763-772.

33. Sulcaj L, Rizza A, Glauber M, et al. Influence of involvement of anterior leaflet versus posterior leaflet on residual regurgitation as assessed by transesophageal echocardiography in patients undergoing valve repair for mitral regurgitation due to mitral valve prolapse. Cardiovasc Ultrasound. 2009;7(1):54.

34. Topilski Y, Grigioni F, Sarano ME. Clinical prognostic value of secondary mitral valve regurgitation. In Secondary Mitral Valve Regurgitation. Springer-Verlag London Ltd. 2015. p. 13-18
International Journal of General Medicine

\section{Publish your work in this journal}

The International Journal of General Medicine is an international, peer-reviewed open-access journal that focuses on general and internal medicine, pathogenesis, epidemiology, diagnosis, monitoring and treatment protocols. The journal is characterized by the rapid reporting of reviews, original research and clinical studies across all disease areas.
The manuscript management system is completely online and includes a very quick and fair peer-review system, which is all easy to use. Visit http://www.dovepress.com/testimonials.php to read real quotes from published authors. 